\title{
Gamma Radiation Induced Formation of Iodine Monochloride in Iodine in Some Aromatic Chlorinated Solvents
}

\author{
P. S. KOLTE* , D.V. PARWATE and S. A. BHANGE \\ Department of Chemistry, Rashtrasant Tukadoji Maharaj Nagpur University, \\ Nagpur-440 033, India \\ prernakolte@gmail.com
}

Received 28 July 2013 / Accepted 30 August 2013

\begin{abstract}
Gamma radiation induced formation of $\mathrm{ICl}$ in aerated and deaerated solutions of iodine in some aromatic chlorinated solvents has been studied for different concentrations and $\gamma$ dosages. G values for formation of $\mathrm{ICl}$ and decomposition of $\mathrm{I}_{2}$ were determined in gamma radiolysis of aerated and deaerated solutions of $\mathrm{I}_{2}$ in 1,2-dichlorobenzene(1,2-DCB), 1,3-dichlorobenzene(1,3-DCB), 2-chlorotoluene, 3-chlorotoluene and benzotrichloride. $\mathrm{G}(\mathrm{ICl})$ values have been found to decrease in the following order 2-chlorotoluene $<3$-chlorotoluene $<1$,2-DCB $<1,3$-DCB $<$ benzotrichloride. $\mathrm{G}(\mathrm{ICl})$ is slightly higher in aerated solutions than in deaerated solutions and is found to be dependent on the structure of the parent organic molecule.
\end{abstract}

Keywords: Aromatic chlorinated solvents, Iodine monochloride, $G$-value

\section{Introduction}

In recent years, the addition of reactive solutes to liquids being irradiated has been extensively applied as a technique for scavenging free radicals intermediates. The radical scavenging using $I_{2}$ in various chlorinated organic solvents has been a subject of detailed investigations ${ }^{1-5}$ in the past. However, no detailed study has been studied in aromatic chlorinated solvents.

In the present work, we have investigated gamma radiation induced formation of $\mathrm{ICl}$ in 1,2-DCB, 1,3-DCB, 2-chlorotoluene, 3-chlorotoluene and benzotrichloride at different concentrations of $I_{2}$ in presence and absence of oxygen.

\section{Experimental}

All the chemicals used were of AR grade. Freshly prepared solutions of $\mathrm{I}_{2}$ of $0.4 \mathrm{mM}, 0.8 \mathrm{mM}$ and $1.2 \mathrm{mM}$ in aromatic chlorinated solvents as mentioned above were air saturated for 15 min prior to irradiation.

The steady-state irradiations were carried out with Cobalt-60 Gamma Chamber - 900 housed in Nuclear Chemistry laboratory, Department of Chemistry, Rashtrasant Tukadoji 
Maharaj Nagpur University, Nagpur. The dose rate of the Co-60 source during the course of work was $\sim 0.5 \mathrm{kGy} / \mathrm{h}$. The dose rate was measured using Fricke dosimetry with $\mathrm{G}\left(\mathrm{Fe}^{3+}\right)=$ 15.6. Dose correction for aromatic chlorinated solvents was applied using expression:

$$
D_{M}=D_{D} \frac{(Z / A)_{M}}{(Z / A)_{D}}
$$

Where $\mathrm{Z} / \mathrm{A}$ is the mean ratio of sum of atomic numbers and molecular weight of the medium and the dosimeter solution respectively. An aliquot of each solution was exposed to successively increasing dosages depending on the appearance of ICl. Stoppered irradiation cells made of corning glass and standard B-19 joints were used to minimize solvent evaporation. Post irradiation absorbance spectra were recorded on Elico SL 210 Double beam UV-Visible spectrophotometer. The spectra of unirradiated sample solutions were recorded simultaneously. The same method was carried out for solutions of $\mathrm{I}_{2}(0.8 \mathrm{mM})$ through which $\mathrm{N}_{2}$ was passed for 15 minutes prior to irradiation.

\section{Results and Discussion}

The visible spectra of non-irradiated solutions of $I_{2}$ in aromatic chlorinated solvents mentioned above exhibit characteristic maxima at $\sim 515 \mathrm{~nm}$ showing presence of $\mathrm{I}_{2}$. However, after irradiation, $\mathrm{I}_{2}$ starts disappearing with subsequent appearance of new characteristic maxima indicating the formation of ICl. These spectra cross with each other at the isobestic point indicating the presence of two species $\mathrm{I}_{2}$ and $\mathrm{ICl}$ simultaneously. Typical absorption spectra for different concentrations of $\mathrm{I}_{2}$ at various dosages are shown in Figure 1 .

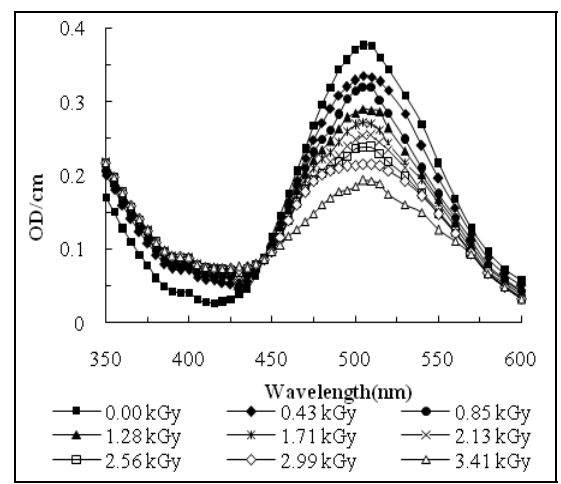

Figure 1. Absorption spectra of $\mathrm{I}_{2}$ solution in 2-chlorotoluene at different dosages for $0.4 \mathrm{mM}$ initial $\mathrm{I}_{2}$ concentration

Spectral characteristic of solutions of $I_{2}$ in chlorinated solvents are given in Table 1 .

Table 1. Spectral characteristic of $I_{2}$ solutions in various aromatic chlorinated solvents

\begin{tabular}{lccc}
\hline Solvents & $\begin{array}{c}\text { Absorption } \\
\text { maxima of } \mathrm{I}_{2} \\
\lambda_{\max } \mathrm{nm}\end{array}$ & $\begin{array}{c}\text { Absorption } \\
\text { maxima of ICl } \\
\lambda_{\max } \mathrm{nm}\end{array}$ & $\begin{array}{c}\text { Isobestic point of } \\
\mathrm{I}_{2} \text { and ICl nm }\end{array}$ \\
\hline 1,2-DCB & 510 & 425 & 450 \\
1,3- DCB & 510 & 420 & 440 \\
2-Chlorotoluene & 505 & 400 & 445 \\
3-Chlorotoluene & 505 & 395 & 440 \\
Benzotrichloride & 510 & 440 & 450 \\
\hline
\end{tabular}


The formation of $\mathrm{ICl}$ and disappearance of $\mathrm{I}_{2}$ at increasing dosages were calculated from two simultaneous equations $\mathrm{s}^{5,6}$.

$$
\begin{aligned}
& {[\mathrm{Abs}]_{430}=40.6\left[\mathrm{I}_{2}\right]+128[\mathrm{ICl}]} \\
& {[\mathrm{Abs}]_{515}=918\left[\mathrm{I}_{2}\right]+59.8[\mathrm{ICl}]}
\end{aligned}
$$

Where, absorbance values were directly obtained from spectra. The amount of ICl formed and $\mathrm{I}_{2}$ decomposed at different irradiation dosages were calculated using equations (2) and (3) and plotted to give yield dose curves. It was observed that as the concentration of $\mathrm{I}_{2}$ in chlorinated solvents increases, the dose required to convert iodine into $\mathrm{ICl}$ also increases. Figure 2 shows a plot of absorbed dose required for formation of $\mathrm{ICl}$ from $\mathrm{I}_{2}$ in 1,2-DCB, 1,3-DCB, 2-chlorotoluene, 3-chlorotoluene and benzotrichloride.

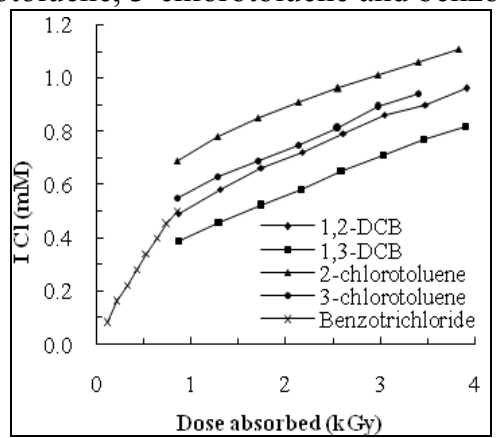

Figure 2. Correlation of dose absorbed and $\mathrm{ICl}$ formed from $\mathrm{I}_{2}$ in 1,2-DCB, 1, 3-DCB, 2chlorotoluene, 3-chlorotoluene and benzotrichloride

A linear relationship with good coefficient of correlation $(\mathrm{R}=0.991,0.998,0.988,0.997$ and 0.996 for 1,2-DCB, 1,3-DCB, 2-chlorotoluene, 3-chlorotoluene and benzotrichloride respectively) was observed. Thus, it is inferred that $\mathrm{ICl}$ formation from $\mathrm{I}_{2}$ in aromatic chlorinated solvents varies directly as the function of absorbed dose.

\section{Variation of $G\left(-I_{2}\right)$ and $G(I C l)$ with dose absorbed}

A summary of variation of $\mathrm{G}\left(-\mathrm{I}_{2}\right)$ and $\mathrm{G}(\mathrm{ICl})$ for different concentrations of $\mathrm{I}_{2}$ in aromatic chlorinated solvents is given in Table 2 .

Table 2. Variation of $\mathrm{G}\left(-\mathrm{I}_{2}\right)$ and $\mathrm{G}(\mathrm{ICl})$ values at various $\mathrm{I}_{2}$ concentrations in different aromatic chlorinated solvents

\begin{tabular}{lccccc}
\hline \multirow{2}{*}{ Solvent } & $\begin{array}{c}\text { Initial Conc. of } \\
\mathrm{I}_{2} \mathrm{mM}\end{array}$ & $\begin{array}{c}\text { Absorbed } \\
\text { dose }(\mathrm{kGy})\end{array}$ & $\mathrm{G}\left(-\mathrm{I}_{2}\right)$ & $\mathrm{G}(\mathrm{ICl})$ & $\Delta \mathrm{ICl} / \Delta \mathrm{I}_{2}$ \\
\cline { 2 - 6 } & & \multicolumn{4}{c}{ Aerated } \\
\hline \multirow{3}{*}{0.4} & 0.49 & 3.65 & 18.58 & \\
& & 0.98 & 2.42 & 9.29 & 1.66 \\
& & 1.47 & 0.94 & 6.91 & \\
& & 0.95 & 0.82 & 6.07 & \\
& \multirow{2}{*}{0.8} & 1.31 & 3.57 & 16.10 & \\
& & 2.18 & 0.90 & 14.92 & 1.83 \\
& 3.48 & 0.22 & 10.97 & \\
\hline
\end{tabular}




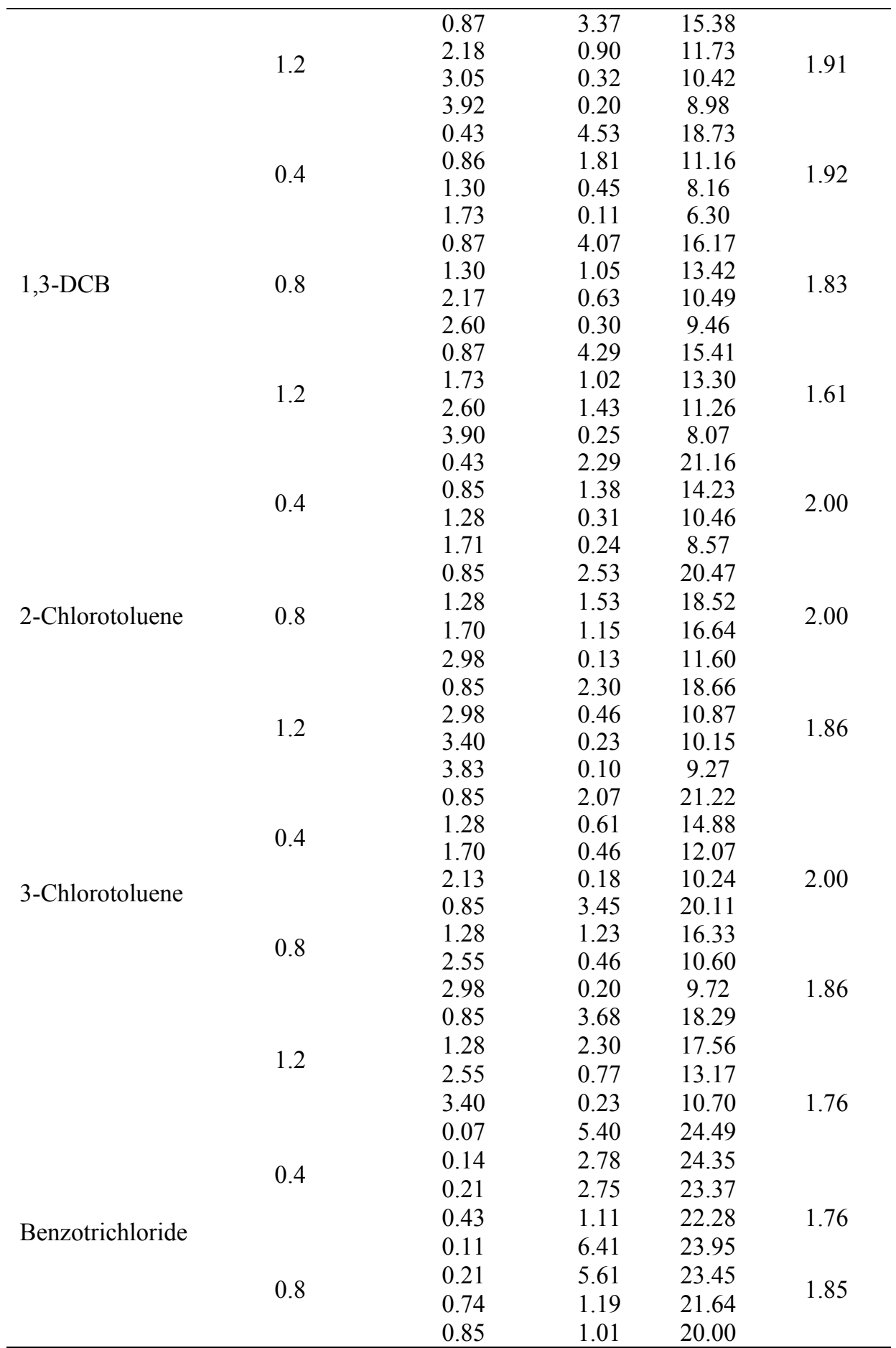

Contd. . 


\begin{tabular}{|c|c|c|c|c|c|}
\hline & & 0.14 & 6.97 & 23.89 & \\
\hline & 12 & 0.28 & 6.86 & 22.97 & 187 \\
\hline & 1.2 & 1.13 & 1.38 & 19.76 & 1.82 \\
\hline & & 1.27 & 0.92 & 19.30 & \\
\hline & & Deaerated & & & \\
\hline & & 0.85 & 1.84 & 13.90 & \\
\hline $12 \mathrm{DCP}$ & 08 & 1.28 & 1.38 & 12.68 & 157 \\
\hline $1,2-\mathrm{DCB}$ & 0.8 & 1.70 & 0.92 & 12.25 & 1.57 \\
\hline & & 2.13 & 0.46 & 11.85 & \\
\hline & & 0.84 & 2.33 & 14.43 & \\
\hline $13 \mathrm{DCR}$ & 08 & 1.26 & 1.86 & 11.59 & 150 \\
\hline $1,3-D C B$ & 0.8 & 2.10 & 0.37 & 8.29 & 1.50 \\
\hline & & 2.94 & 0.20 & 6.56 & \\
\hline & & 0.85 & 3.93 & 15.47 & \\
\hline Chlontolyon & 08 & 2.11 & 0.74 & 10.31 & 101 \\
\hline z-cniorotoluene & 0.8 & 2.54 & 0.39 & 9.21 & 1.91 \\
\hline & & 3.38 & 0.12 & 7.27 & \\
\hline & & 0.21 & 9.23 & 16.16 & \\
\hline Donzetriolonido & $0:$ & 0.42 & 6.00 & 15.42 & 160 \\
\hline Benzotrichloride & 0.8 & 0.85 & 0.69 & 14.69 & 1.63 \\
\hline & & 0.90 & 0.62 & 13.71 & \\
\hline
\end{tabular}

The plots of radiation chemical yield ( $G$-values) and dose absorbed in various aromatic chlorinated solvents has been compared as shown in Figure 3.
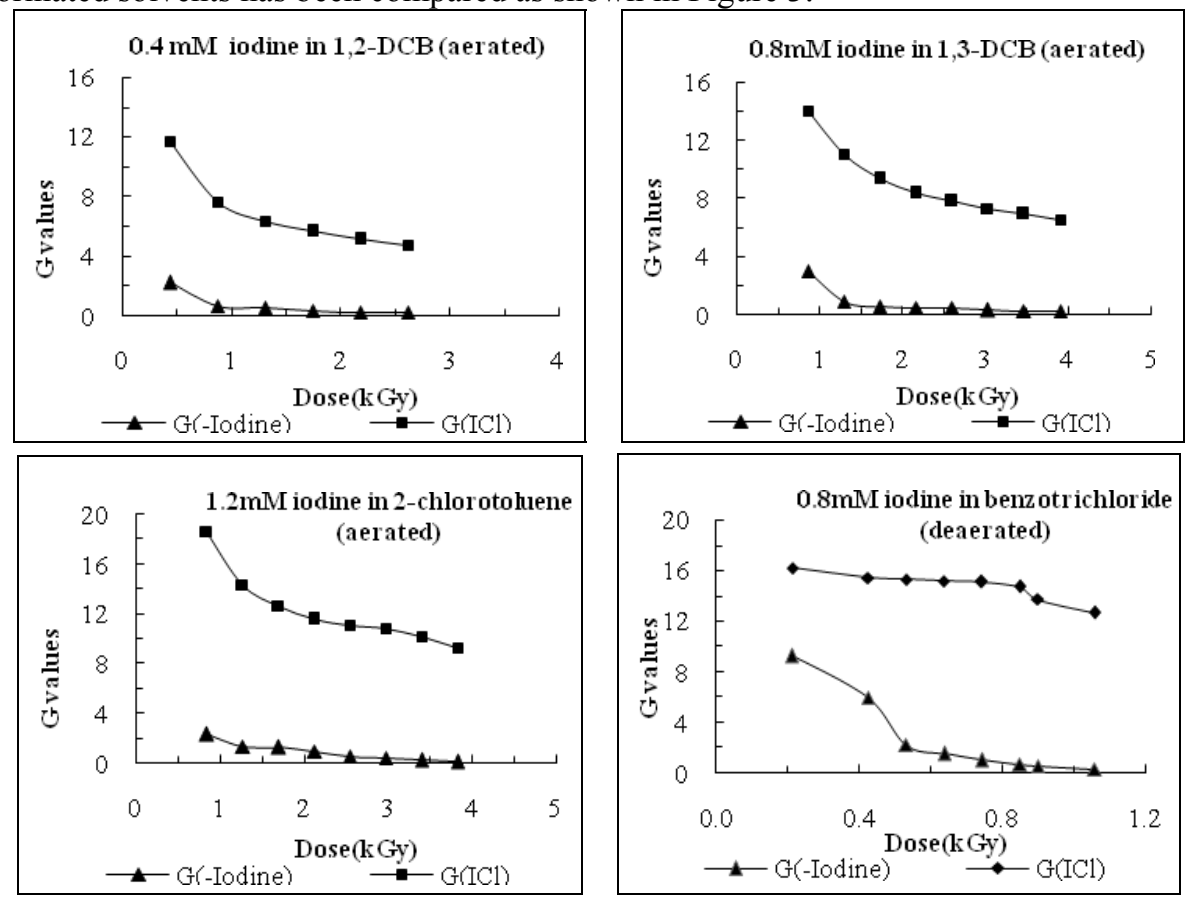

Figure 3. Variation of $\mathrm{G}\left(-\mathrm{I}_{2}\right)$ and $\mathrm{G}(\mathrm{ICl})$ with dose absorbed in aerated 1,2-DCB, 1,3-DCB, 2-chlorotoluene and deaerated benzotrichloride 
From Figure 3, it is observed that $\mathrm{G}\left(-\mathrm{I}_{2}\right)$ and $\mathrm{G}(\mathrm{ICl})$ values decrease with increase in concentration due to decrease in number of $\mathrm{ICl}$ molecules formed with increasing concentration of $\mathrm{I}_{2}$. As the number of $\mathrm{Cl}$ atoms available for formation of $\mathrm{ICl}$ at higher concentration of $\mathrm{I}_{2}$ becomes less, it is quite likely that less number of ICl molecules are formed at higher $I_{2}$ concentrations. It is noticed that $G$ values suddenly drop at higher dosages. Presumably, at higher dosages, a part of $\mathrm{ICl}$ is getting decomposed and it reaches to saturation value.

The formation of $\mathrm{ICl}$ and $\cdot \mathrm{Cl}$ as one of the products was observed by Bibler ${ }^{8,9}$ in radiolysis of air-saturated solution of $\mathrm{I}_{2}$ in $\mathrm{CCl}_{4}$. In the present work, radiolysis of $\mathrm{I}_{2}$ solutions in aromatic chlorinated solvents also results in $\mathrm{ICl}$ as the major product due to radical reaction.

In aromatic chlorinated solvents, very high dose is required to effect a colour change and for formation of $\mathrm{ICl}$, a part of energy gets deposited on benzene ring which is resonance stabilized and hence, $\mathrm{Ar}-\mathrm{Cl}$ bond is not broken easily. The dose required to effect colour change and for formation of $\mathrm{ICl}$ in $\mathrm{C}_{6} \mathrm{H}_{5} \mathrm{CCl}_{3}$ is less as compared to $\mathrm{C}_{6} \mathrm{H}_{4} \mathrm{Cl}_{2}$ and $\mathrm{Cl}$ $\mathrm{C}_{6} \mathrm{H}_{4} \mathrm{CH}_{3}$ as $\mathrm{Cl}$ in $\mathrm{C}_{6} \mathrm{H}_{5} \mathrm{CCl}_{3}$ is not directly attached to benzene ring.

In case of $\mathrm{I}_{2}$ in chlorobenzenes, $\mathrm{ICl}$ is the main product containing iodine although very small amounts of $\mathrm{C}_{6} \mathrm{H}_{6}, \mathrm{C}_{6} \mathrm{H}_{5} \mathrm{C}_{6} \mathrm{H}_{5}, \mathrm{C}_{6} \mathrm{H}_{5} \mathrm{C}_{6} \mathrm{H}_{5} \mathrm{Cl}, \mathrm{C}_{6} \mathrm{H}_{4} \mathrm{ICl}$ and $\mathrm{C}_{6} \mathrm{H}_{5} \mathrm{I}(\mathrm{G}<0.5)$ have also been detected ${ }^{10,11}$. The primary dissociation reaction may take place directly through dissociation of excited molecules or indirectly through ionic intermediates ${ }^{12}$. Radiolysis of chlorotoluenes possibly lead to ionization, excitation and electrons react by dissociative electron attachment ${ }^{13}$.

There may be formation of several other products like $\mathrm{HCl}$, higher chlorohydrocarbons or oxides of chlorine but these were not identified. The possibility of chain reaction mechanism cannot be ruled out due to high $\mathrm{G}(\mathrm{ICl})$ values. Due to certain constraints of the experimental set up in our laboratory, the formation of other products could not be identified.

Thus, it is observed that in radiolysis of aromatic chlorinated compounds at one stage or the other, ${ }^{-} \mathrm{Cl}$ is one of the products formed as a result of carbon-halogen and carbonhydrogen bond rupture ${ }^{14}$. It seems that presence of aromatic ring does not stabilize the aromatic chlorinated compounds towards radiolysis.

Radiolysis of $\mathrm{I}_{2}$ in 1,2-DCB, 1,3-DCB, 2-chlorotoluene, 3-chlorotoluene and benzotrichloride solutions under aerated conditions gives significantly higher $\mathrm{G}(\mathrm{ICl})$ than in absence of oxygen. This additional yield possibly derives due to the addition of molecular oxygen to the radicals generated by the reactions of the primary radiation-induced radicals, $\mathrm{e}^{-}$with the respective aromatic chlorinated solvents ${ }^{15,16}$.

\section{Conclusion}

The concentration of $\mathrm{ICl}$ varies linearly with the dose absorbed at lower dosages with good coefficient of correlation. After a certain dose, a deviation in $\mathrm{G}\left(-\mathrm{I}_{2}\right)$ and $\mathrm{G}(\mathrm{ICl})$ values are observed for every solvent and each concentration. This could be due to $\mathrm{C}-\mathrm{Cl}$ bond dissociation energy.

The observed values of $\mathrm{G}(\mathrm{ICl})$ in presence of oxygen were found to be slightly higher than those in absence of oxygen due to the addition of molecular oxygen to the radicals generated by the reactions of the primary radiation-induced radicals, $\mathrm{e}^{-}$, with the respective aromatic chlorinated solvents. 
$\mathrm{G}\left(-\mathrm{I}_{2}\right)$ and $\mathrm{G}(\mathrm{ICl})$ are found to be almost constant for every solvent and each iodine concentration. Radiolytic decomposition of $\mathrm{I}_{2}$ in aromatic chlorinated solvents and formation of $\mathrm{ICl}$ is observed to be dependent on the structure of the parent organic molecule.

\section{Acknowledgement}

Thanks are due to the Head of the Department of Chemistry for providing laboratory and irradiation facilities.

\section{References}

1. Taghipour F and Evans G J, Radiat Phys Chem., 1997, 49(2), 257-264; http://dx.doi.org/10.1016/S0969-806X(96)00065-5.

2. Abramson F P, Buckhold B M and Firestone R F, J Am Chem Soc., 1962, 84(12), 2285-2588; DOI:10.1021/ja00871a002

3. Truszkowski S and Shostenko A G, Nucleonika, 2003, 48(1), 41.

4. Schmid S, Krajnik P, Quint R and Solar S, Radiat Phys Chem., 1997, 50(5), 493-502; http://dx.doi.org/10.1016/S0969-806X(97)00075-3

5. Kale S M, Parwate D V, Das Sarma I B and Batra R J, Int J Chem Sci Technol., 2011, 1(4), 183.

6. Kolthoff I M and Sandell E B, Textbook of Quantitative Inorganic Analysis , $3^{\text {rd }}$ Ed., Macmillan Co., New York, 1952, 629.

7. Manek T, Wankhade H K, Parwate D V and Garg A N, Radiochem Radioanal Lett., 1983, 58(5-6), 373-384.

8. Bibler N E, J Phys Chem., 1971, 75(1), 24-30; DOI:10.1021/j100671a004

9. Bibler N E, J Phys Chem., 1973, 77(2), 167-170; DOI:10.1021/j100621a005

10. Choi S U and Willard J E, J Phys Chem., 1962, 66(6), 1041-1049;

DOI: $10.1021 / \mathrm{j} 100812 \mathrm{a} 018$

11. Takriti S, Water Qual Res J Canada, 2004, 39, 245.

12. Maclachlan A and Maclarthy R L, J Am Chem Soc., 1962, 84(13), 2519.

13. Weiss J and Collins C H, Radiat Res., 1966, 28(1), 1-12; DOI:10.2307/3571923

14. Truszkowski S and Shostenko A G, High Energy Chem., 2008, 42(2), 89-91; DOI:10.1134/S0018143908020045

15. Alfassi Z B, Mosseri S and Neta P, J Phys Chem., 1989, 93(4), 1380-1385; DOI:10.1021/j100341a040

16. Pimblott S M, Milosavljevic B H and LaVerne J A, J Phys Chem A, 2005, 109(45), 10294-10301; DOI:10.1021/jp0537613 